\title{
An Analysis of Lexical Style and Cultural Connotation in Students' English Writing in China
}

\author{
Chunqin Zhang \\ College of Humanities and Foreign Languages \\ Xi'an University of Science and Technology \\ 58 Yan Ta Road, Xi'an 710054 Shaanxi, China \\ javalongbow@163.com
}

\begin{abstract}
This paper probes lexical errors in Chinese college students' writing based on text analysis. The lexical errors involve lexical style and lexical cultural connotation. The choice of words and expression in students' writing is not consistent with the type of writing and students tend to ignore the cultural connotation of words and expressions in conveying their ideas. It then explores the reasons why students are insensitive in the choice of words in writing and find that these errors are mainly caused by the interlingual transfer and the intralingual transfer in second language learning process. Finally, it suggests that teachers need to cultivate their own cultural awareness and increase students lexical stylistic and cultural awareness in English writing.
\end{abstract}

Keywords—writing, lexicon, style, culture

\section{INTRODUCTION}

Writing is an important form of discourse communication. Chinese students' English writing is a cross-language and cultural exchange activity. Its purpose is to make readers of English-speaking countries or readers of English understand their ideas. English writing as a way of language expression is influenced by the culture in which the language is. Each nation has its own unique social system, living environment, religious beliefs, customs, traditions and traditions, etc. The cultural patterns of the same ethnic group are reflected in the language level. In the long history of human society, people have formed their unique beliefs, habits, national character, psychology, system. These factors directly affect our writing and thinking in a subconscious way. Therefore, in learning a foreign language, learners have to pay much attention the culture of the language as well the language itself.

As one of the five basic skills that students must master in the learning process, writing is an important way to measure students' English learning. The author discovered in many years of English teaching that there are various problems in students' English writing, such as lexical selection, syntactic structure, paragraph organization, and layout. In these highfrequency errors, grammatical and structural errors of a text can be corrected have been given high priority, while lexical errors are much more difficult to correct and thus are ignored to great degree. Lexical errors in student's wring are mostly resulted from teachers' and students' neglect of lexical style and cultural connotation. This article takes the essays of second-year English majors as an example to analyze the main problems in the English lexical style and cultural connotation of students' English writing.

\section{LEXICAL STYLE}

The linguistic style, also known as the linguistic form, is a system of "a variant of speech function under the influence of contextual types, and a language-specific material system that manifests itself in specific context types., ${ }^{,[1]}$ In real life, people communicate in accordance with different languages, communicative purposes, and communicative objects. These exchanges involve not only the content of the language, but also the language itself. In order to achieve different communication goals, people will consciously choose different language materials and expressions, so that the language materials with the same meaning will be differentiated in the communicative function and form different characteristic systems and methods in the specific language application process. There is also a gradual difference in style. Although these expressions have little or no difference in the meaning, once their systems and methods are formed, they will have a relatively fixed use environment and cannot be mixed with each other. Therefore, it can be said that the genre is "a choice of synonymous variants that differ in the circumstances of use, ${ }^{,[2]}$ it is 'based on synonymy, and the object of study is the differences in style between the language components. ${ }^{\text {.[3] }}$

Styles can be divided into multiple categories based on different criteria. Martin Joos (1962), founder of English stylistics, divides English into five languages from the perspective of pragmatics in his book The Five Clocks, namely frozen (formally), formal (formal), consultative (deliberative style), casual (optional style), and intimate (intimate style). However, under normal circumstances, for the sake of simplicity, English genre is generally divided into formal genre and informal genre. This division is reflected in vocabulary, which is the difference between formal and informal vocabulary. Both have their own obvious grammatical and lexical features, and there are distinct differences in style: the former is more standardized, formal, and rigorous in usage; the latter is more arbitrary. In general, due to historical reasons, foreign vocabularies in English such as Latin, Greek, French, etc. are in a higher status and are official vocabulary. Some basic vocabulary originating from the native language has a low status and is an informal vocabulary. For example, When the concept of "horse" is 
expressed in English, the word "steed" is an official vocabulary," "horse " is more neutral, and " nag " is an informal vocabulary. Another example is the following two sets of words:

TABLE I. EXAMPLES OF LEXICAL GENRE

\begin{tabular}{|l|l|}
\hline A & \multicolumn{1}{|c|}{ B } \\
\hline begin & commence \\
\hline choice & alternative \\
\hline end & terminate \\
\hline down & depreciation \\
\hline despair & desperation \\
\hline payment & remuneration \\
\hline
\end{tabular}

Group A is the core vocabulary in English, originating from Anglo-Saxon, and group B is a foreign vocabulary. In contrast, group A is short and has a low status, and is often used in spoken and colloquial languages. Group B has a complex structure, long words, and a small scope of application. It is commonly used in written languages.

Stylistic meaning is an important aspect of lexical meaning. In English learning, vocabulary size is one of the important criteria for checking students' English proficiency. For secondyear college English majors, the vocabulary they possess is relatively small. Most of them are basic vocabulary and simple words that are colloquial. These results in students' compositions are mostly simple words and loosely structured. Stylistic analysis has a lower degree of formality and is more likely to be colloquial. ${ }^{[4]}$ For example, in an essay about students' online problems, there is one piece:

Well, I don't think it is ok for a student to surf the net for hours. If you spend a lot of time on it, you will certainly lose yourself.

In these two sentences, students use well, ok, and you (in the personal pronouns of the denotation, he, one, we are more formal, and you, yourself are informal.) etc. The vocabulary is obviously inconsistent with the special context of student writing.

Due to the influence of traditional exam oriented education, Chinese students' mastery of English words still lies in the memory of spelling and the corresponding meaning in Chinese, and does not give full attention to the stylistic meaning of the vocabulary. Therefore, the lack of sense of writing is a prominent problem in students' English writing. Students lack the concept of style in English vocabulary, and have vague understanding of specific words, such as word position, rhetoric and emotional color. They often pay attention to the meaning, spelling and pronunciation of words in the process of vocabulary memorization, but they do not pay enough attention to the stylistic feature of vocabulary. In addition, for second year English Majors, they have begun to come into contact with more formal materials and vocabulary. However, because of the incomplete understanding of the lexical features, even when they are exposed to these words, they are also rarely identified and differentiated in terms of language style, which leads to students' oral and written confounding in English writing. In the composition of the low language, the words are mixed with the high language vocabulary, or the opposite. This causes the phenomenon of language dislocation. The whole article seems to be neither in the class nor in the style.

My mother is a very soft and brave woman. She loves us with all her heart, and never criticizes us violently but instructs us with great patience. She is at the same time very brave. After my father kicked the bucket, we're in an awkward situation, but she doesn't subdue to her fate and becomes more courageous and stubborn. When I ask for her permission to leave school to help her to do the housework, she doesn't grant me. I'm moved and resolute to do my best for her.

The meaning of this passage is clear, and there is no grammatical error. However, readers feel a sense of dislocation from time to time in the process of reading. The reason is that this sense of dislocation is mainly caused by stylistic problems. The description of the mother is basically a category of daily life, so it is not appropriate to use some too formal words in style. However, the author has repeatedly chosen some formal or even professional words. For example, the word "grant" has a high status and is usually used for formal occasions (such as legal documents, documents, etc.) to indicate the seriousness of the context. Although the meaning of the word is clearly expressed in the quotation, it is not in harmony with the whole article. It can be replaced by words like "agree", "approve" and other words. In addition to the word "grant", this type of word has appeared many times in the text, such as violently, instruct, subdue, resolute and so on. In contrast, the author has also selected the colloquial vocabulary that is relative to the above formal words. For example, in the "After my father kicked the bucket" clause, "kicked the bucket" is a idiomatic slang, which is obviously incompatible with the full tone of the full text, and cannot express the author's sad and sad feelings properly.

Of course, from the historical point of view of the evolution of lexical meaning, there is no absolute standard for the division of formal and informal languages. They often differ from each other and interact with each other. However, from a certain period of time, there will be a relatively fixed use and environment in the formation of the lexical meaning, and the stability and independence of the words will be gradually strengthened in the process of use, and the other languages are repellent. Therefore, it requires teachers to pay attention to the cultivation of the students' style consciousness in the teaching of English writing. On the one hand, it makes the students understand the types of writing, the style of writing, the purpose and the object. On the other hand, it guides the students to realize that the proper meaning of the vocabulary is also a balance, besides the correctness of the grammar. An important indicator of the level of writing.

\section{LEXICAL CONNOTATION}

Besides the improper use of lexical meaning, a common problem in Chinese students' English writing is the lack of cultural awareness.

Fundamentally speaking, Chinese students' English writing is a cross-cultural discourse exchange. English and Chinese 
belong to two cultural circles, which are very different in almost all aspects. The social and historical environment and cultural background on which they can produce and depend on are completely different in many aspects. As a carrier of culture, every aspect of language is inevitably influenced by culture. Therefore, when writing in English, students must take full account of the cultural background and way of thinking in English speaking countries. At the same time, English and Chinese belong to two different language systems, each with a unique set of rules. These two cultural and linguistic rules are sometimes consistent but sometimes conflicting. This conflict is reflected in vocabulary, and there are overlapping words, parallel words, vacancy words and conflict words. Due to the influence of native culture and language habits, students often have some pragmatic errors when writing in English. Specific to the choice of words, these errors are mainly manifested in the students' understanding of the cultural meaning of English vocabulary (that is, the concomitant meaning). The following is an example from student writing.

I am a top student in my class, so I gain my teachers' green-eye, my classmates' admiration and someone's red-eye.

In this sentence, there are two "eye", one is the teacher's "green-eye", the other is some people's "red-eye". These two "eye" are likely to confuse the readers of English speaking countries: how can teachers envy their students? And why do some people suffer from insomnia? However, if contacted with Chinese, students' intention will be very clear. In the Chinese expression habit, "red eye" can express "jealousy", such as "red eye disease", so students think of "jealousy" and "red eye" in English literal translation "red-eye". In addition, the word "favor" in the formal expression of "like" or "attach" to a person in Chinese, and the "green" word in English is closer to the corresponding word "green", so that students naturally use "green-eye" to express the meaning of "favor". However, if we pay more attention to the differences between the two languages and the cultural differences behind them, we will find that "green-eye" means "jealousy" in English and "red-eye" is only the result of insomnia.

\section{Here is another example:}

Smoking does harm to your body. If you do not stop smoking, you will be dangerous.

Here, we can understand that "stop smoking” means "do not smoke any more". However, in English "stop smoking" means smoking is forbidden in a public place, while quit smoking means to "do not smoke any more". Meanwhile, in the sentence "you will be dangerous" means you are a dangerous person and will do harm to others. However, the students actually want to express the meaning that if you do not quit smoking, it will do harm to your health and you will be in a critical condition. As Chinese readers, we can guess what he means in accordance with the context. However, it is not easy for native speakers of English to understand it. Then the writing does not make sense to them and it will fail to convey his idea.

There is always a lexical correspondence between the languages of different nationalities. Understanding and mastering this relationship is the basic condition for crosscultural communication. The comparative study of the ethnic cultural semantics of Chinese and English corresponding words is of great significance to the improvement of crosscultural communication and language understanding. However, "correspondence" is not equivalent to "equivalence". Even if the rational concept of expression is the same, it often produces different associative meanings because of different cultures. For example, the word "guanxi" in Chinese is not completely equivalent to "relation" in English. For example, the word "relation" in the phrase "He has overseas relations" refers to a specific person in Chinese, while in English, the word "relation" represents an abstract concept that is different from Chinese.

The reasons why students tend to confuse the words in English writing are due to their lack of cultural awareness. In writing, students tend to form a Chinese sentence in their minds, then select a word according to the meaning of the Chinese language, or refer to the English vocabulary that corresponds to the Chinese meaning by means of a tool book, and choose one of them to be filled in a position that is filled in a series of words with similar meanings. In the process of word selection, students usually do not compare and discriminate the cultural meaning of words because of their lack of cultural awareness. The result is that the cultural meaning of the selected words is more than or less, or even completely divorced from the meaning they have to express, so that the whole composition appears to be composed of English vocabulary, and its core is the way of thinking and expression in the Chinese language.

\section{SUGGESTIONS FOR IMPROVING STUDENTS’ WRITING}

As the final written output, writing is an important way to test student's language learning, the improper choice of English words in Chinese students' writing shows that languages are not simple translation of words. Cultural differences between the two languages are much more complicated than expected. Without a good mastery of lexicon style and connotation, students are not able to produce a satisfactory piece of writing. Therefore it is vital for teachers as well as students pay attention to cultural differences between Chinese and English in teaching and learning process.

First, teachers should increase cross-culture teaching and raise students' cultural awareness. Students 'acquisition of Western writing methods and patterns requires external reinforcement and guidance. In the English teaching materials, the proportion of teaching content that specifically introduces western culture is relatively small, and it is not yet fully aware of the important role of culture in language learning. So it is of great significance to teach students the cultural difference between English words and their equivalence in Chinese, introducing the certain contexts a word can be used and the contexts in which it will not be proper to use. In the simple Chinese-English bilingual dictionary, the cultural style and connotation of English words are mostly not fully explained. So a great deal of work is left for teachers to do. The crossteaching of words takes time and energy, but once the cultural awareness of students are established, they may take the initiative to study and explore on their own. 
Second, teachers need to raise their own cultural awareness and cultivate their own ability of cross-cultural communication. In the process of English teaching, teachers should become intermediaries and interpreters between two different cultures. In foreign language teaching, it is very important for teachers to understand and become familiar with the cultural connotation and cultural background attached to certain language components in the two languages, and it is sometimes a very critical accomplishment. Teachers themselves should strive to improve their own cultural cultivation, consciously cultivate their own insights into the two cultures, familiar with the two cultures involved in foreign language teaching. While they teach language itself, they are supposed to teach language and culture knowledge as well, so that language teaching and cultural teaching can go hand in hand.

Third, in addition to introducing students to the cultural implications of language itself, we should also introduce the customs and habits of Western countries, people's lifestyles, religious beliefs, thinking patterns and other cultural backgrounds. The content of western culture is permeated and integrated in every link of teaching. Teachers should summarize the differences between Chinese and western cultures, form systematic cultural rules, and then teach them to students to enhance their sensitivity and insight into British and American culture, and cultivate students' awareness of cultural communication. Cultural teaching in foreign language teaching is to allow students to have a sense of cultural exchange through the study of western culture, so as to achieve the interaction between the mother tongue culture and the second language culture, make them actively and consciously absorb and produce authentic English expressions to achieve accurate information transmission.

\section{CONCLUSION}

Writing is a continuous writing process of how to find the most effective language for ideological and emotional communication. It is a complex cycle of psychological cognitive process, thought creation process and social interaction process. For students, writing in both mother tongue and English language can be challenging. It not only consolidates the knowledge of the language that has been learned, also it is an important means of communication. The native language culture will have a negative migration to the English composition of Chinese students. Although it is difficult to completely rule out this kind of negative migration, studying the cultural differences that affect writing can be very extensive. It plays down the interference of native language culture, makes English writing teaching more relevant and applicable, and makes students write more authentic English article. In the course of English writing teaching, teachers should increase the content of western cultural knowledge teaching, Integrating cultural teaching into language teaching, improving students' cultural awareness and increase writing practice to effectively improve his English writing ability.

The errors of the style and culture in the students' English writing are mainly caused by the interlingual transfer and the intralingual transfer in the second language learning process. For Chinese students, interlingual transfer is the influence of Chinese on English. It usually occurs in the early stage of English learning. During this period, the English language that the students mastered did not yet form a system, so in English writing, they could only think in Chinese and make sentences in Chinese rules and phrases. Thus Chinglish came into being. For these mistakes, teachers should help students to correct them as soon as possible, and enable them to develop the habit of thinking in English as soon as possible. After a certain period of English learning, there will be intralinguistic transfer. For these errors teachers should guide students to realize that almost every rule has exceptions. In English writing, we should pay attention to some special uses, rather than the simple mechanical application of rules.

\section{REFERENCES}

[1] Wang Dechun, Chen Chen. Modern rhetoric [M]. Shanghai: Shanghai foreign language education press, 2001.

[2] Wei Pengpeng. A comprehensive comparison between English and Chinese texts [M]. Shanghai: Shanghai foreign language education press, 2000.

[3] Zhao Xiufeng. Stylistic writing and genre based writing teaching, [J]. foreign language teaching, 2004 (5), 75-8.

[4] Cai Jigang 4. A contrastive study of English and Chinese writing [M]. Shanghai: Fudan University press, 2001. 